\title{
Assessment of a short phylogenetic marker based on comparisons of 3' end 16S rDNA and 5' end 16S-23S ITS nucleotide sequences of the Bacillus cereus group
}

\author{
Sabarimatou Yakoubou ${ }^{1,2}$, Jean-Charles Côté ${ }^{1 *}$ \\ ${ }^{1}$ Agriculture and Agri-Food Canada, Research Centre, Gouin Blvd, St-Jean-sur-Richelieu, Canada; *Corresponding Author: \\ Jean-Charles.Cote@agr.gc.ca; \\ ${ }^{2}$ Département des Sciences Biologiques, Université du Québec à Montréal, Succ.“Centre-Ville” Montréal, Canada.
}

Received 28 May 2010; revised 30 June 2010; accepted 5 July 2010.

\section{ABSTRACT}

A short phylogenetic marker previously used in the reconstruction of the Order Bacillales and the genus Bacillus was assessed here at a lower taxa level: species in the Bacillus cereus group: $B$. anthracis, $B$. cereus, $B$. thuringiensis and $B$. weihenstephanensis. This maker is $220 \mathrm{bp}$ in length. It is a combination of $150 \mathrm{bp}$ at the $3^{\prime}$ end of the 16S rDNA and $70 \mathrm{bp}$ at the 5' end of the 16S-23S ITS sequence. Three additional Bacillus species, $B$. halodurans, $B$. licheniformis and $B$. subtilis, and Clostridium tetani were included for comparison purposes. A total of eight bacterial species and 12 strains were analyzed. A bootstrapped neighbor-joining tree was inferred from comparative analyses of all allelic sequences of the bacterial species and strains under study. Based on its topology, four major Groups were revealed at the $90 \%$ nucleotide sequence identities, Group I to IV. Group I contains all alleles of the Bacillus cereus group. Group II contains all alleles of $B$. halodurans. Group III contains all alleles of $B$. licheniformis and $B$. subtilis. Group IV contains all alleles of Clostridium tetani. The 220 bp phylogenetic marker used here could resolve different species from different genera. At the genus level, distant species could be distinguished. Very closely-related species, however, were undistinguishable. Species in the $B$. cereus group, most notably $B$. cereus, $B$. anthracis and $B$. thuringiensis, could not be distinguished. After successfully inferring the phylogenies of the Order Bacillales and the genus Bacillus, we have met the resolving limit of this short phylogenetic marker: $B$. cereus, B. anthracis and $B$. thuringiensis.
Keywords: Bacillus cereus; 16S rDNA; 16S-23S ITS; Phylogeny

\section{INTRODUCTION}

The Bacillus cereus group comprises six genetically highly related species: $B$. cereus sensu stricto, $B$. anthracis, $B$. thuringiensis, $B$. weihenstephanensis, $B$. mycoides [1] and B. pseudomycoides [2]. They are Grampositive, rod-shaped, endospore-forming, either obligate or facultative aerobic bacteria [1].

Bacillus cereus is a ubiquitous soil bacterium. It can be a contaminant of a variety of foods: meats, vegetables and dairy products $[3,4]$. It can cause diarrheal, and emetic food poisoning syndromes [5]. It can also be the etiologic agent of some opportunistic infections [6,7]. $\mathrm{Bac}$ illus anthracis is the etiologic agent of anthrax, an acute disease in herbivorous mammals, transmissible to other animals, including humans [8]. This species has been studied and developed as a biological weapon [9]. Virulent strains of $B$. anthracis carry two plasmids, pXO1 $(181 \mathrm{~kb})$ and pXO2 $(96 \mathrm{~kb})$ which may be transmitted to others members of Bacillus cereus group [10]. Bacillus thuringiensis is an insect pathogen. It is characterized by the synthesis upon sporulation of a parasporal inclusion body. This inclusion body is made of proteins, the $\delta$-endotoxins, which are toxic to several insect larvae $[11,12]$ and other invertebrates [13]. B. thuringiensis formulations have been developed for the control of insect pests in agriculture and forestry [14-16] and for the control of insect vectors of human diseases such as malaria, yellow fever, onchocerciasis, etc [17]. Bacillus weihenstephanensis is a psychotolerant species characterized by the ability to grow at $7{ }^{\circ} \mathrm{C}$ and the absence of growth at $43^{\circ} \mathrm{C}$. It is also characterized by the presence of specific signature sequences on the 16S rRNA gene (small subunit ribosomal RNA gene) and the $\operatorname{csp} A$ gene (gene encoding the major cold shock protein) [18]. B. mycoides is char- 
acterized by the formation of rhizoid colonies and the absence of motility [19]. B. pseudomycoides is phenotypically similar to $B$. mycoides and is distinguished by DNA relatedness and fatty acid composition [2].

The 16S rDNA is the macromolecule of choice in the reconstruction of bacterial phylogenies [20-24]. The $16 \mathrm{~S}$ rDNA, however, cannot distinguish among species in the Bacillus cereus group [25,26]. Genomic approaches have been used in an attempt to elucidate the genetic diversity of three highly closely related species in the $B$. cereus group: B. cereus, B. anthracis and B. thuringiensis. They appear as a single species on the basis of genetic evidence [27].

In a previous study, a 220 bp marker was developed and used to infer the phylogeny of species in the genus Bacillus and closely-related genera [28]. This marker was a combination of the last $150 \mathrm{bp}$ at the 3' end of the $16 \mathrm{~S}$ rDNA and the first $70 \mathrm{bp}$ at the 5 ' end of the $16 \mathrm{~S}$ 23S rDNA internal transcribed spacer (ITS). More recently, we assessed the usefulness of the $220 \mathrm{bp}$ marker at a higher taxonomic level, the Order Bacillales [29]. This marker showed several advantages over the use of $16 \mathrm{~S}$ rDNA sequences or the generation of extensive phenotypic and genotypic data in phylogenetic analyses. First, the $150 \mathrm{bp}$ at the 3 ' end of the $16 \mathrm{~S}$ rDNA allowed discrimination among distantly related species. Owing to its higher rate of nucleotide substitutions, the $70 \mathrm{bp}$ at the 5 , end of the 16S-23S rDNA (ITS) added discriminating power among closely related species from same genus and closely related genera from same family. Because of its higher percentage of nucleotide sequence divergence than the $16 \mathrm{~S}$ rDNA, the 220 bp marker could better discriminate among closely related Bacillus [28] and $\mathrm{Ba}$ cillales [29] species. Second, the method was simple, rapid, suited to large screening programs and easily accessible to most laboratories. Third, the marker also revealed species which appeared misassigned and for which additional characterization appeared warranted.

In the current study, we further analyze the resolving power of this short marker in inferring phylogenies at a much lower taxa level: the Bacillus cereus group.

\section{MATERIALS AND METHODS}

\subsection{Bacterial Species and Strains}

Four species in the Bacillus cereus group: B. anthracis, $B$. cereus, B. thuringiensis and B. weihenstephanensis were analyzed. Three additional Bacillus species, B. halodurans, B. licheniformis and B. subtilis, and Clostridium tetani were included for comparison purposes. A total of eight bacterial species and 12 strains were analyzed (Table 1). They were selected on the basis that their complete genome sequences were freely available in $\mathrm{Ge}-$ nBank at the National Center for Biotechnology Information (NCBI) completed microbial genomes database (http://www.ncbi.nlm.nih.gov/genomes/lproks.cgi,Augus t 2009). Bacillus mycoides and B. pseudomycoides were not included because their complete genome sequences have not been determined.

Table 1. Bacterial species used in this study.

\begin{tabular}{|c|c|c|c|}
\hline Genera & Species & Strain & GenBank accession no. \\
\hline \multirow[t]{11}{*}{ Bacillus } & anthracis & Ames & AE016879 \\
\hline & & Ames Ancestor & AE017334.2 \\
\hline & & Sterne & AE017225.1 \\
\hline & cereus & ATCC 14579 & AE016877.1 \\
\hline & & ATCC 10987 & AE017194.1 \\
\hline & & E33L & СР000001.1 \\
\hline & thuringiensis serovar konkukian & $97-27$ & AE017355.1 \\
\hline & weihenstephanensis & KBAB4 & NC_010184.1 \\
\hline & halodurans & $\mathrm{C}-125$ & BA000004.3 \\
\hline & licheniformis & ATCC 14580 & AE017333.1 \\
\hline & subtilis subsp. subtilis & 168 & AL009126.3 \\
\hline Clostridium & tetani & E88 & AE015927.1 \\
\hline
\end{tabular}




\subsection{Sequences}

The 16S rDNA and 16S-23S ITS for the 12 bacterial species and strains were retrieved from GenBank, for a total of 129 allelic sequences. The last $150 \mathrm{bp}$ at the 3' end of $16 \mathrm{~S} \mathrm{rDNA}$ and the first $70 \mathrm{bp}$ at the 5 ' end of 16S-23S ITS were merged into a single $220 \mathrm{bp}$ sequence for each of the 129 alleles under study as described before [28]. This $220 \mathrm{bp}$ sequence will be used as a phylogenetic marker for the 12 bacterial species and strains under study.

\subsection{Phylogenetic Analyses}

All 129 allelic sequences were aligned using ClustalW [30] (data not shown). A neighbor-joining tree was constructed [31], based on the alignment of the 129 alleles of the $220 \mathrm{bp}$ sequence. The tree was bootstrapped using 1,000 random samples. The neighbor-joining tree was drawn and printed with Tree Explorer, all components of the Molecular Evolutionary Genetics Analysis (MEGA, version 3.1) software package [32].

\section{RESULTS AND DISCUSSIONS}

In a previous study, a 220 bp sequence was developed as a DNA marker and used to infer the phylogeny of species in the Gram-positive genus Bacillus and closelyrelated genera [28]. This marker was a combination of the last $150 \mathrm{bp}$ at the 3' end of the 16S rDNA and the first $70 \mathrm{bp}$ at the 5' end of the 16S-23S rDNA internal transcribed spacer (ITS). More recently, we assessed the usefulness of the $220 \mathrm{bp}$ marker by extending its analyses at a higher taxonomic level, the Gram-positive Order Bacillales [29]. In parallel, a similar marker was used to infer the phylogeny of the Gram-negative Class $\gamma$-proteobacteria [33]. In the current study, we further analyze the resolving power of this marker in inferring the phylogeny at a much lower taxa level: the Bacillus cereus group.

A bootstrapped neighbor-joining phylogenetic tree was inferred from comparative analyses of the $220 \mathrm{bp}$ marker from the 129 alleles from the bacterial species and strains under study (Figure 1). Four major Groups were revealed based on the topology of the neighborjoining tree at the $90 \%$ nucleotide sequence identities, Group I to IV. Group I contains all alleles of the species in the Bacillus cereus group. Group II contains all alleles of $B$. halodurans. Group III contains all alleles of $B$. licheniformis and B. subtilis. Group IV contains all alleles of Clostridium tetani. Based on nucleotide sequence identities, sub-groups and branches can be revealed. Group I can be sub-divided into three sub-groups at the $95 \%$ nucleotide sequence identities. Sub-group I-1 encompasses 27 alleles from the $B$. anthracis strains, 36 alleles from the $B$. cereus strains, 11 alleles from $B$. thuringiensis and one allele from $B$. weihenstephanensis. Sub-group I-2 encompasses six alleles from B. anthracis, two alleles from $B$. cereus and one allele from $B$. thuringiensis. Sub-group I-3 encompasses 12 alleles from $B$. weihenstephanensis. A branch corresponding to an allele from $B$. weihenstephanensis is present between sub-groups I-2 and I-3. Group II contains all eight alleles from $B$. halodurans. They show at least $20 \%$ nucleotide sequence divergences with alleles from the other Bacillus species. Group III contains all alleles from B. licheniformis and $B$. subtilis. It can be sub-divided into two sub-groups at the $95 \%$ nucleotide sequence identities. Sub-group III-1 encompasses all seven alleles from $B$. licheniformis. Sub-group III-2 encompasses all ten alleles from $B$. subtilis. Group IV contains all six alleles from Clostridium tetani. These alleles show at least $26 \%$ nucleotide sequence divergence with alleles from species and strains in the genus Bacillus.

In accordance with our previous work on the Order Bacillales, the 220 bp sequence used as a phylogenetic marker was able to group alleles from same species for $B$. halodurans, B. licheniformis, B. subtilis, and Clostridium tetani, respectively. However, this $220 \mathrm{bp}$ sequence could not group most alleles from same species, exclusive of alleles from others, for the $B$. cereus group. Subgroup I-1 is heterogeneous. It contains alleles from all four species from the $B$. cereus group. The close proximity of B. cereus, B. anthracis and B. thuringiensis is in agreement with previous works based on whole-genome DNA hybridization [34], pulsed-field gel electrophoresis (PFGE) [35], multilocus enzyme electrophoresis (MEE) [36], amplified fragment length polymorphism (AFLP) fingerprinting [37] and multilocus sequence typing (MLST) $[38,39]$, which showed that all three species are genetically highly related. They appear as a single species on the basis of genetic evidence [27]. Sub-groups I-2 is more homogeneous. It mostly contains alleles from $B$. anthracis. Sub-groups I-3 is homogeneous. It only contains alleles from $B$. weihenstephanensis. As shown earlier, on the genus Bacillus [28] and the Order Bacillales [29], this $220 \mathrm{bp}$ sequence contains $150 \mathrm{bp}$ at the 3' end of $16 \mathrm{~S}$ rDNA which allowed discrimination among distantly related species and $70 \mathrm{bp}$ at the 5 ' end of $16 \mathrm{~S}-23 \mathrm{~S}$ ITS which, owing to its higher percentage of nucleotide sequence divergence, added resolving power among closely related species.

Here, species in the $B$. cereus group, most notably $B$. cereus, B. anthracis and $B$. thuringiensis, are too closely related to be discriminated with the $220 \mathrm{bp}$ sequence previously used as a phylogenetic marker. Our work, however, has shown that the alleles in sub-group I-3 could distinguish $B$. weihenstephanensis from all other species. 


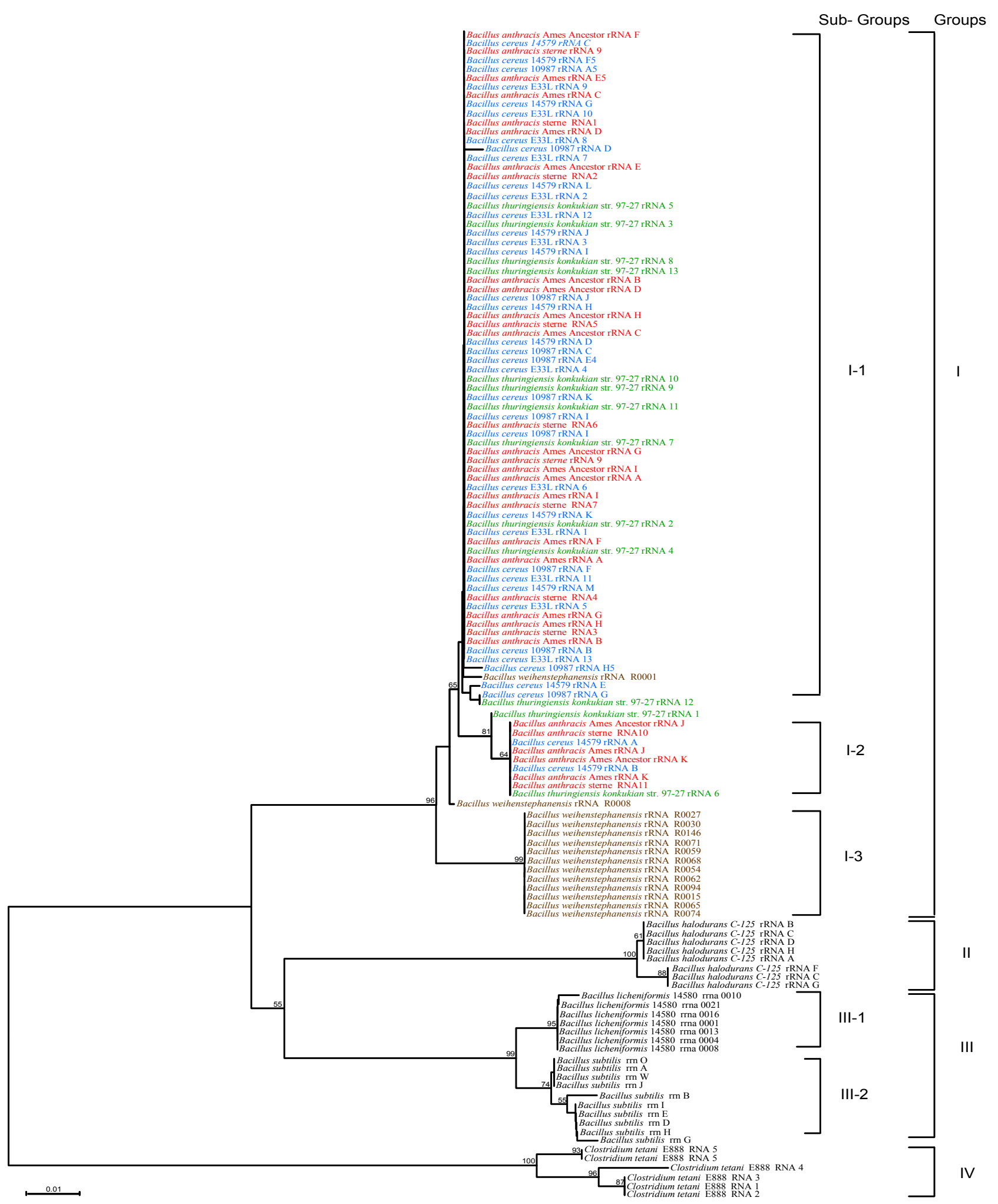

Figure 1. Bootstrapped neighbor-joining tree inferred from comparative alignment of the $220 \mathrm{bp}$ marker from the 129 alleles from the 12 bacterial species and strains under study. Major groups are indicated in capital roman numerals. Sub-groups are indicated in arabic numerals. Bootstrap values higher than $50 \%$ are indicated (expressed as percentage of 1000 replication). The horizontal bar represents $1 \%$ nt difference. Bacillus anthracis, B. cereus, B thuringiensis and B. weihenstephanensis's alleles are written in red, blue, green and brown, respectively. B. halodurans, B. licheniformis, B. subtilis and Clostridium tetani's alleles are written in black ink. 


\section{CONCLUSIONS}

Previous genetic analyses have shown that $B$. cereus, $B$. anthracis and $B$. thuringiensis should be regarded as a single species. We have shown here that a 220 bp marker, used to reconstruct the phylogeny of the Order Bacillales and the family Bacillaceae, was unable to discriminate between these three highly-related species. We have reached the limit of the resolving power of the $220 \mathrm{bp}$ sequence as a phylogenetic marker: $B$. cereus, $B$. anthracis and B. thuringiensis.

\section{REFERENCES}

[1] Claus, D. and Berkeley, R.C.W. (1986) Genus Bacillus Cohn, 1872. In: Sneath, P.H.A., Mair, N.S., Sharpe, M.E. and Holt. J.G. Eds., Bergey's Manual of Systematic Bacteriology, The Williams \& Wilkins Co., Baltimore, 2, 1105-1139.

[2] Nakamura, L.K. (1998) Bacillus pseudomycoides sp. nov. International Journal of Systematic Bacteriology, 48(3), 1031-1035.

[3] Drobniewski, F.A. (1993) Bacillus cereus and related species. Clinical Microbiology Reviews, 6(4), 324-338.

[4] Schoeni, J.L. and Wong, A.C.L. (2005) Bacillus cereus food poisoning and its toxins. Journal of Food Protection, 68(3), 636-648.

[5] Kramer, J.M. and Gilbert, R.J. (1989) Bacillus cereus and other Bacillus species. In: Doyle, M.P., Ed., Foodborne Bacterial Pathogens, Marcel Dekker, Inc., New York, 2150.

[6] Das, T., Choudhury, K., Sharma, S., Jalali, S., Nuthethi, R. and the Endophthalmitis Research Group (2001) Clinical profile and outcome in Bacillus endophthalmitis. Ophthalmology, 108(10), 1819-1825.

[7] Le Scanff, J., Mohammedi, J.I., Thiebaut, A., Martin, O., Argaud, L. and Robert, D. (2006) Necrotizing gastroenteritis due to Bacillus cereus in an immunocompromised patient. Infection, 34(2), 98-99.

[8] Logan, N.A. and De Vos, P. (2009) Genus I. Bacillus Cohn 1872, $174^{\mathrm{AL}}$. In: De Vos, P., Garrity, G.M., Jones, D., Krieg, N.R., Ludwig, W., Rainey, F.A., Schleifer, K.H. and Whitman, W.B. Eds., Bergey's Manual of Systematic Bacteriology, 2nd Edition, Springer, New York, 3, 21-128.

[9] Inglesby, T.V., O'Toole, T., Henderson, D.A., Bartlett, J.G., Ascher, M.S., Eitzen, E., Friedlander, A.M., Gerberding, J., Hauer, J., Hughes, J., McDade, J., Osterholm, M.T., Parker, G., Perl, T.M., Russell, P.K. and Tonat, K. (2002) Anthrax as a biological weapon: Updated recommendations for management. The Journal of the American Medical Association, 287(17), 2236-2252.

[10] Turnbull, P.C.B. (2002) Introduction: Anthrax history, disease and ecology. In: Koehler, T., Ed., Anthrax, Springer-Verlag, Berlin, 1-20.

[11] Höfte, H. and Whiteley, H.R. (1989) Insecticidal crystal proteins of Bacillus thuringiensis. Microbiological Reviews, 53(2), 242-255.

[12] Garcia-Robles, I., Sánchez, J., Gruppe, A., Martínez-Ramírez, A.C., Rausell, C., Real, M.D. and Bravo, A. (2001) Mode of action of Bacillus thuringiensis PS86Q3 strain in hymenopteran forest pests. Insect Biochemistry and Molecular Biology, 31(9), 849-856.

[13] Feitelson, J.S. (1993) The Bacillus thuringiensis family tree. In: Kim, L. Ed., Advanced Engineered Pesticides, Marcel Dekker Inc., New York, 63-71.

[14] Schnepf, H.E., Crickmore, N., Van Rie, J., Lereclus, D., Baum, J., Feitelson, J., Zeigler, D.R. and Dean, D.H., (1998) Bacillus thuringiensis and its pesticidal crystal proteins. Microbiology and Molecular Biology Reviews, 62(3), 775-806.

[15] Otvos, I.S., Armstrong, H. and Conder, N. (2005) Safety of Bacillus thuringiensis var. kurstaki, applications for insect control to humans and large mammals. In: Côté, J.-C., Otvos, I.S., Schwartz, J.-L. and Vincent, C. Eds., Proceedings of the 6th Pacific Rim Conference on the Biotechnology of Bacillus thuringiensis and its Environmental Impact. Montréal, 30 October-3 November 2005, 45-59.

[16] Bravo, A., Gill, S.S. and Soberon, M. (2007) Mode of action of Bacillus thuringiensis Cry and Cyt toxins and their potential for insect control. Toxicon, 49(4), 423-435.

[17] Guillet, P., Chandre F. and Mouchet, J. (1997) L'utilisation des insecticides en santé publique: état et perspectives. Médecine et Maladies Infectieuses, 27(5), 552557.

[18] Lechner, S., Mayr, R., Francis, K.P., Prüß, B.M., Kaplan, T., Wießner-Gunkel, E., Stewart Gordon, S.A.B. and Scherer, S. (1998) Bacillus weihenstephanensis sp. nov. is a new psychrotolerant species of the Bacillus cereus group. International Journal of Systematic Bacteriology, 48(4), 1373-1382.

[19] Nakamura, L.K. and Jackson, M.A. (1995) Clarification of the taxonomy of Bacillus mycoides. International Journal of Systematic Bacteriology, 45(1), 46-49.

[20] Woese, C.R., Kandler, O. and Wheelis, M.L. (1990) Towards a natural system of organisms: Proposal for the domains Archea, Bacteria and Eucarya. Proceedings of the National Academy of Sciences, USA, 87(12), 45764579.

[21] Amann, R., Ludwig, W. and Schleifer, K.H. (1995) Phylogenetic identification and in situ detection of individual microbial cells without cultivation. Microbiological Review, 59(1), 143-169.

[22] Cilia, V., Lafay, B. and Christen, R. (1996) Sequence heterogeneities among $16 \mathrm{~S}$ ribosomal RNA sequences and their effect on phylogenetic analyses at species level. Molecular Biolology and Ecology, 13(3), 451-461.

[23] Goto, K., Omura, T., Hara, Y. and Sadaie, Y. (2000) Application of the partial $16 \mathrm{~S}$ rDNA sequence as an index for rapid identification of species in the genus Bacillus. Journal of General and Applied Microbiology, 46(1), 1-8.

[24] Sacchi, C.T., Whitney, A.M., Mayer, L.W., Morey, R., Steigerwalt, A., Boras, A., Weyant, R.S. and Popovic, T. (2002) Sequencing of 16S rRNA gene: A rapid tool for identification of Bacillus anthracis. Emerging Infectious Disease, 8(10), 1117-1123.

[25] Ash, C., Farrow, J.A., Dorsch, M., Stackebrandt, E. and Collins, M.D. (1991) Comparative analysis of Bacillus anthracis, Bacillus cereus, and related species on the basis of reverse transcriptase sequencing of $16 \mathrm{~S}$ rRNA. International Journal of Systematic Bacteriology, 41(3), 343-346. 
[26] Ash, C., Farrow, A.E., Wallbanks, S. and Collins, M.D. (1991) Phylogenetic heterogeneity of the genus Bacillus revealed by comparative analysis of small-subunit-ribosomal RNA sequences. Letters in Applied Microbiology, 13(4), 202-206.

[27] Vilas-Boas, G.T., Peruca, A.P. and Arantes, O.M. (2007) Biology and taxonomy of Bacillus cereus, Bacillus anthracis, and Bacillus thuringiensis. Canadian Journal of Microbiology, 53(6), 673-687.

[28] Xu, D. and Côté, J.-C. (2003) Phylogenetic relationships between Bacillus species and related genera inferred from comparison of 3' end 16S rDNA and 5' end 16S-23S ITS nucleotide sequences. International Journal of Systematic and Evolutionary Microbiology, 53(3), 695-704.

[29] Yakoubou, S., Xu, D. and Côté, J.-C. (2010) Phylogeny of the order Bacillales inferred from 3' 16S rDNA and 5' 16S-23S ITS nucleotide sequences. Natural Science, 2(9), 990-997.

[30] Thompson, J.D., Higgins, D.G. and Gibson, T.J. (1994) CLUSTALW: Improving the sensitivity of progressive multiple sequence alignment through sequence weighting, positions-specific gap penalties and weight matrix choice. Nucleic Acids Research, 22(22), 4673-4680.

[31] Saitou, N. and Nei, M. (1987) The neighbor-joining method: A new method for reconstructing phylogenetic trees. Molecular Biology and Evolution, 4(4), 406-425.

[32] Kumar, S., Tamura, K. and Nei, M. (2004) MEGA3: Integrated software for molecular evolutionary genetics analysis and sequence alignment. Brief Bioinformatic, 5(2), 150-163.

[33] Yakoubou, S. and Côté, J.-C. (2010) Phylogeny of $\gamma$-proteobacteria inferred from comparisons of 3 ' end 16S rRNA gene and 5 ' end 16S-23S ITS nucleotide sequences. $\mathrm{Na}$ tural Science, 2(6), 535-543.

[34] Kaneko, T., Nozaki, R. and Aizawa, K. (1978) Deoxyribonucleic acid relatedness between Bacillus anthracis, Bacillus cereus and Bacillus thuringiensis. Microbiology and Immunology, 22(10), 639-641.

[35] Carlson, C.R., Caugant, D.A. and Kolsto, A.-B. (1994) Genotypic diversity among Bacillus cereus and Bacillus thuringiensis strains. Applied and Environmental Microbiology, 60(6), 1719-1725.

[36] Helgason, E., Caugant, D.A., Olsen, I. and Kolsto, A.-B. (2000) Genetic structure of population of Bacillus cereus and Bacillus thuringiensis isolates associated with periodontitis and other human infections. Journal of Clinical Microbiology, 38(4), 1615-1622.

[37] Ticknor, L.O., Kolsto, A.B., Hill, K.K., Keim, P., Laker, M.T., Tonks, M. and Jackson, P.J. (2001) Fluorescent amplified fragment length polymorphism analysis of Norwegian Bacillus cereus and Bacillus thuringiensis soil isolates. Applied and Environmental Microbiology, 67(10), 4863-4873.

[38] Helgason, E., Tourasse, N.J., Meisal, R., Caugant, D.A. and Kolsto, A.B. (2004) Multilocus sequence typing scheme for bacteria of the Bacillus cereus group. Applied and Environmental Microbiology, 70(1), 191-201.

[39] Olsen, J., Skogan, G., Fykse, E., Rawlinson, E., Tomaso, H., Granum, P. and Blatny, J. (2007) Genetic distribution of 295 Bacillus cereus group members based on adk-screening in combination with MLST (Multilocus Sequence Typing) used for validating a primer targeting a chromosomal locus in B. anthracis. Journal of Microbiological Methods, 71(3), 265-274. 